\title{
Indicadores epistemológicos do "Brazil-Medico": Educação e Educação Física ${ }^{1}$
}

\section{Epistemologies pointers of "Brazil-Medico": Education and Physical Education}

\author{
Maria Isabel Brandão de S. Mendes ${ }^{2}$ \\ Terezinha Petrucia da Nóbrega ${ }^{2}$
}

\begin{abstract}
RESUMO
O artigo evidencia relações entre a Educação escolar e a Educação Física com base em indicadores epistemológicos relacionados aos cuidados com o corpo em busca de saúde, presentes no final do século XIX e início do XX. O material empírico utilizado foi o periódico "Brazil-Medico", do período de 1887-1923. Este estudo tece reflexões sobre cuidados com a saúde na Educação e aponta elementos sobre a sistematização da Educação Física, tendo como foco o método racional. Conclui-se que a Educação Física contribuiu com a interiorização de cuidados com o corpo em busca de saúde na Educação escolar, chamando a atenção para a vivacidade das crianças. A sistematização da Educação Física através do método racional contribuiu com o reconhecimento da existência da cultura física, das expressões do corpo, numa época em que prevalecia um ensino pautado na memorização e na imobilidade.
\end{abstract}

Palavras-chave: saúde; Educação Física; corpo.

\footnotetext{
ABSTRACT

The article evidences relations between school education and Physical Education on the basis of the epistemologies pointers related to body care

DOI: $10.1590 / 0104-4060.40471$

1 Esta pesquisa contou com apoio financeiro da Coordenação de Aperfeiçoamento de Pessoal de Nível Superior - CAPES.

2 Universidade Federal do Rio Grande do Norte. Programa de Pós-Graduação em Educação Física. Campus Universitário, Lagoa Nova. Natal, Rio Grande do Norte, Brasil. Av. Sen. Salgado Filho, n³ 3000. CEP: 59072-970.E-mail: isabelmendes@ufrnet.breE-mail: pnobrega@ufrnet.br
} 
seeking health, present in the end of the $19^{\text {th }}$ century and beginning of the $20^{\text {th }}$ century. The empirical material used was the periodical "Brazil-Medico" in the period of 1887-1923. This study weaves reflections on the cares with health in education and it points elements on the systematization of Physical Education, having as its focus the rational method. It is concluded that Physical Education contributed with the internalization of body care in search of health in the pertaining to school education, calling the attention to the children's vivacity. The systematization of Physical Education through the rational method contributed with the recognition of the existence of physical culture, of body expressions, at a time when an education ruled in memorization and immobility prevailed.

Keywords: health; Physical Education; body.

\section{Introdução}

Diversos estudos demonstram a notória influência dos médicos-higienistas para a Educação no final do século XIX e início do XX. É nesse cenário que a Educação Física fundamentada no pensamento médico-higienista constrói suas bases científicas e passa a ser reconhecida no cenário escolar como uma prática social que desde a sua origem intervém socialmente por meio do ensino de exercícios físicos, jogos e esportes. (AZEVEDO, 1920, 1960; GÓIS JUNIOR; LOVISOLO, 2005; GONDRA, 2000, 2003; SOARES, 1994; VAGO, 1999a, 1999b).

Nesse período encontramos investigações sobre a influência dos médicos-higienistas na Educação Física e suas relações com a Educação. Considerando a importância da temática e sua amplitude, ainda não inteiramente esgotada em estudos científicos na área, elegemos como corpus de análise os artigos do periódico "Brazil-Medico" que tratam da questão em debate.

Esse periódico é reconhecido como um referencial importante para a medicina brasileira, bem como é considerado um espaço de divulgação da Educação Física no período indicado, uma vez que vinculava artigos sobre as práticas de exercícios físicos. Cabe ressaltar que nesse período os médicos contribuíam com a produção de conhecimento sobre exercícios físicos, como é notório observar no "Brazil-Medico".

O "Brazil-Medico" era publicado semanalmente e estava vinculado à Faculdade de Medicina do Rio de Janeiro, além de possuir vínculo com a Sociedade de Medicina e Cirurgia do Rio de Janeiro. (BECKER; PAZTMANN; GROSS, 2003; FERREIRA; MAIO; AZEVEDO, 1998; SCHWARCZ, 1993). 
Este artigo evidencia relações entre a Educação escolar e a Educação Física com base em indicadores epistemológicos relacionados aos cuidados com o corpo em busca de saúde, tendo como material empírico o periódico "Brazil-Medico".

Primeiramente é tecida uma reflexão sobre os cuidados com a saúde na Educação escolar e em seguida são apresentados elementos epistemológicos sobre a sistematização do conhecimento da Educação Física, tendo como foco o método racional. Para terminar são tecidas algumas considerações sobre o referido estudo.

\title{
A Educação Física e os cuidados com a saúde
}

\begin{abstract}
Nas visitas que tenho feito a diversas escolas em hora de recreio, vejo frequentemente o modo por que elle é dado. Em alguns casos, as professoras deixam as creanças na própria sala de aula, permittindo lhes apenas um pouco mais de movimento. Em outros, consentem que vão para uma sala especial ou para o quintal, mas ahi lhes recommendam que se limitem a passeiar grave e pausadamente. E faz pena ver a monotonia desses recreios tão tristes, onde, á pequena distancia, ninguém suspeitaria, pelo sillencio nelles guardado, que estivesse um bando de creanças. Por isso, ás ultimas horas de classe, os pequeninos estão cabeceando de somno, incapazes de atenção. (HYGIENE..., 1903, p. 137).
\end{abstract}

No início do século XX, uma matéria no "Brazil-Medico" nos chama a atenção. Ela mostra que no horário do recreio era possível ficar em sala de aula ou num quintal, no entanto, era consentida pouca movimentação para as crianças. O que prevalecia era o silêncio dos pequenos.

Num contexto em que os alunos passavam a maior parte do tempo sentados, decorando o que era estudado dentro de suas salas de aula, a imobilidade e a falta de cuidados com o corpo imperavam. Como consequência, o ambiente escolar era visto como uma prisão, inclusive nos espaços do recreio.

A descrição do ambiente escolar é encontrada numa circular escrita pelo Diretor Geral da Instrução Pública Municipal do Rio de Janeiro, Medeiros e Albuquerque, direcionada aos inspetores escolares. Essa circular foi publicada no "Brazil-Medico", em 1903, para ressaltar a preocupação da diretoria com o desenvolvimento e a vida das crianças e os problemas da Educação Infantil. (HYGIENE..., 1903). 
Outro aspecto do espaço escolar é destacado no "Brazil-Medico", o fato de os alunos necessitarem ficar nas aulas de 5 a 6 horas sem intervalo, tendo que ter atenção fixa nas atividades escolares. Para o Dr. Clemente Ferreira, o imobilismo, o excesso de esforço mental, o abuso ou a falta de exercícios físicos geravam escoliose devido à fadiga dos músculos dorsais, bem como perturbações no sistema nervoso. (FERREIRA, 1909).

Num editorial sobre o Congresso Internacional das Escolas ao Ar Livre, que se reportava à Educação da criança, foi apresentada a necessidade de reduzir para 4 horas o ensino intelectual. As 2 horas restantes deveriam ser dedicadas à prática da higiene, à educação sensorial e às artes e 1 hora pelo menos por dia deveria ser destinada à Educação Física ao ar livre e à luz solar. Foi ressaltada, ainda, a necessidade dos professores realizarem "classes-passeios", visitas a museus e a monumentos, bem como a necessidade de instalação de um terreno de esportes que permitisse a cultura física e os banhos de sol. (ESCOLAS..., 1922).

É com base nesses argumentos que os médicos do final do século XIX e início do século XX, que publicavam artigos no "Brazil-Medico", defendiam a Educação Física no interior da escola. Eles teciam críticas à pouca mobilidade das crianças, pois estas eram obrigadas a ficar muitas horas atentas às atividades intelectuais. Os médicos defendiam a necessidade da cultura física para as crianças, pois elas precisavam se movimentar. Desse modo, ao contribuírem com a instauração da positividade da saúde na sociedade brasileira, esses médicos tinham interesse no ensino primário, uma vez que objetivavam atender a infância, para garantir o futuro do país.

Como podemos perceber em alguns artigos analisados, os médicos desejavam proteger as crianças do descuido dos pais e dos professores, combater as noções de saúde pautadas nas crendices, tidas como errôneas e também ansiavam reduzir a deterioração física e a degeneração da raça. Com a falta de movimentos, diziam que os alunos se enfraqueciam, não se desenvolviam e tendiam a adquirir doenças, moleza e languidez. (CLARK, 1916, 1923; FERREIRA, 1909; FONTES, 1921; MONCORVO FILHO, 1900; SÁ, 1922).

Os médicos defendiam uma Educação da saúde desde a mais tenra idade, pois a infância, fase de evolução, era compreendida como responsável pela agravação das taras hereditárias, pela aquisição de defeitos, atitudes e imperfeições corporais que precisavam ser refutadas, amenizadas e precavidas. Esses médicos defendiam uma Educação capaz de produzir cidadãos instruídos, civilizados, sadios e vitalizados.

Nesse contexto, a imagem infantil é, em grande parte, redimensionada devido à reação dos higienistas face à mortalidade das crianças, que era considerada sinal de esperança religiosa dos pais. (COSTA, 1999). 
É interessante perceber nos artigos analisados, como alguns médicos brasileiros, que discutiam sobre o ensino da higiene nas escolas primárias, se apropriaram de referenciais da pedagogia ativista, para refutar práticas consideradas ultrapassadas. (CLARK, 1916; MONCORVO FILHO, 1900; PIÇARRA, 1908; SÁ, 1922).

É interessante perceber como esses médicos aproveitaram os fundamentos necessários para alicerçar as metas que defendiam no final do século XIX e início do século XX no Brasil.

Nas primeiras décadas do século XX no Brasil ocorreram reformas nos sistemas de Instrução Pública. Essas reformas educacionais receberam influência do movimento pela Escola Nova que ocorria na Europa e nos Estados Unidos no período entre a primeira guerra mundial e a segunda e ofereceram, aos interessados em renovar a Educação brasileira, um leque de opções de intervenção pedagógica. (CARVALHO, 2000).

Como podemos observar em alguns artigos do "Brazil-Medico", os métodos de ensino baseados na memorização de palavras que eram responsáveis pela aprendizagem da higiene são questionados nessas publicações. (PIÇARRA, 1908; SÁ, 1922).

O principio fundamental - de que os conhecimentos devem ser adquiridos por meio da experiência, e não pela única via da memória - ainda não penetrou, infelizmente no regimen das nossas escolas. Por isso, não admira que os nossos alumnos de instrucção primaria aprendam os rudimentos de hygiene exclusivamente decorando palavra. (PIÇARRA, 1908, p. 326).

A citação do Dr. Ladislão Piçarra demonstra claramente que o que prevalecia ainda no ensino primário era o método de decorar palavras e não a aprendizagem pautada nas experiências vividas.

Para superar o método da memorização, o Dr. Ladislão Piçarra e o Dr. Carlos Sá defendiam o abandono dos livros, a utilização de laboratórios e um método de ensino abalizado pela experiência. Um ensino pela ação, pautado nos métodos das ciências naturais. Além da justificativa de se opor ao desenvolvimento normal do cérebro, o método de memorização deveria ser abandonado por causar na maior parte dos alunos aversão aos estudos. (PIÇARRA, 1908; SÁ, 1922).

Nada se ensina ensinando, mas tudo se ensina fazendo. É o que Dewey, um dos grandes mestres americanos, explica, dizendo que o cérebro deve ser 
excitado pela acção e não pelas palavras. Aliás, outro não é, sinão menos amplo, o methodo froebeliano, em que, por exemplo, pela modelagem em areia, se aprendem os accidentes geographicos no próprio terreno da escola. (SÁ, 1922, p. 22).

Na citação de Dr. Carlos Sá, identificamos que o americano John Dewey e o alemão Friedrich Froebel são mencionados para demonstrar a importância de uma aprendizagem pela ação, pela experiência vivida pelos alunos.

Além de Dewey e Foebel, os estudos de Montaigne e Montessori eram referenciais utilizados no "Brazil-Medico" para superar os métodos de ensino pautados na memorização. O que importava era uma Educação pela ação, com vistas a superar o imobilismo.

Como ressalta Rocha (2000), ao analisar as estratégias elaboradas pelos médico-higienistas, nas décadas iniciais do século XX, através do manual escolar intitulado "Noções de hygiene: livro de leitura para as escolas", o meio de ação preconizado pela Educação era incutir hábitos higiênicos segundo regras de bem viver pautadas no disciplinamento das práticas escolares e na eliminação das práticas de memorização.

Os estudos de Montaigne, Dewey, Foebel e Montessori, citados pelos médicos no "Brazil-Medico" para refutar os métodos de memorização, estão relacionados à pedagogia do ativismo sustentada pelo movimento de renovação da pedagogia nas escolas. Um movimento que tinha como temas característicos o puericentrismo, a valorização do fazer, a motivação, a centralidade do estudo de ambiente, a socialização e o anti-intelectualismo. Nessa pedagogia, a criança tem papel essencial em todo o processo educativo, refutando-se a supremacia do adulto sobre ela. A aprendizagem infantil é guiada por atividades manuais e por jogos, precisando estar ligada a algum interesse por parte da criança e ser desenvolvida na realidade, pois, é o ambiente que a circunda o local ideal para receber estímulos. A socialização é vista como exigência da criança no processo educativo, valorizando-se uma organização mais livre dos conhecimentos por parte do aluno. (CAMBI, 1999).

Essa concepção de Educação busca a superação dos métodos tradicionais de ensino e admite as vivências na aprendizagem, refutando a memorização e o imobilismo, reconhecendo que o corpo não é responsável por erros. Entretanto, continua orientada na concepção intelectualista de aprendizagem e o corpo é visto, então, como acessório no processo de construção do conhecimento. Nessa compreensão, pautada pela fisiologia clássica, o corpo é visto como instrumento para a cognição, e o fenômeno da percepção é reconhecido como uma operação 
de captação de uma realidade externa, mediante um processo de recepção de informações da realidade.

Entretanto, a partir dos artigos analisados, podemos perceber que nem todos os temas característicos da pedagogia ativa interessavam por completo a esses médicos. O que desejavam era refutar a imobilidade a que os alunos estavam sujeitos e propiciar um contato com a natureza, com ar puro, tão almejado numa época em que a vida ao ar livre e a cultura física eram consideradas como capazes de ampliar tanto as funções respiratórias, quanto a resistência aos micróbios. Formar hábitos de saúde só seria possível através da experimentação, pois, o cérebro deveria ser exercitado pela ação, num período em que a ociosidade e a languidez eram extremamente combatidas. (PIÇARRA, 1908; SÁ, 1922).

Era preciso, portanto, ter um corpo e um cérebro sãos e aptos para a instrução. (FERREIRA, 1909; MONCORVO FILHO, 1911). Além de ser instrumento para a cognição, o corpo também era considerado instrumento para a moral. Era necessário introduzir nas crianças hábitos que lhes permitissem conformar-se com o interesse coletivo da Educação da saúde. Fontes (1921) defendia que era necessário incutir:

[...] nos organismos débeis as noções elementares da moral e da hygiene que os possam transformar em seres úteis à coletividade, libertando a sociedade do peso morto do atrazado mental, do retardado no desenvolvimento physico, pasto futuro a todas as lepras moraes e mórbidas que corroem a humanidade civilizada. (FONTES, 1921, p. 100).

Pelo que podemos identificar na citação acima, a infância era vista como período fundamental para o aprendizado das regras de higiene e da moral, com possibilidades de transformação da própria sociedade, considerada atrasada mentalmente e fisicamente.

A maneira encontrada para incutir nas crianças os hábitos que defendiam era o adestramento dos gestos, para que fossem capazes de repeti-los por toda a vida. (SÁ, 1922).

O adestramento era reconhecido como capaz de disciplinar os alunos, de extinguir seus vícios, como a fantasia, o sonho e a desobediência. Só assim, o Dr. Oscar Clark dizia ser possível progredir as nações organizadas, cujos filhos tinham empreendimento e soubessem obedecer ao superior hierárquico. (CLARK, 1916).

Desse modo, como podemos observar nos artigos analisados do "Brazil-Medico", a Educação preconizada pelos médicos traz alguns indicadores da 
Pedagogia Ativa, sendo considerada como sinônimo de formação do caráter através da ação. Uma Educação que tinha como meta melhorar a saúde física e mental dos alunos, para retirar defeitos e imperfeições orgânicas e combater hábitos e práticas viciosas, evitando a formação de cidadãos débeis e tarados e colaborando com a construção de uma raça sadia e culta, bem como com a diminuição da morbidez e da mortalidade através do disciplinamento dos gestos.

A Educação Física alicerçada cientificamente poderia colaborar com a transformação social tão almejada na época. Melhor dizendo, era um elemento extremamente importante para regenerar a raça brasileira. Para modelar os seres humanos e alcançar uma nação perfeita, bela, sem defeitos ou doenças, seria necessário, portanto, direcionar suas ações, o que contribuiu com a instauração do racismo moderno.

O racismo moderno, um racismo biológico e de Estado, exalta as políticas sobre a vida. A vida biológica é estatizada, o biopoder se instaura. O corpo que vive, suporte do nascimento, da morte, da longevidade e da saúde, é controlado para ser inserido no campo produtivo e econômico, servindo, desse modo, para o desenvolvimento da sociedade industrial. As estratégias biopolíticas intentam intervir sobre a maneira de viver, para ampliar a vida, controlar os acidentes, o aleatório, as deficiências. $\mathrm{O}$ direito de morte vai aos poucos perdendo espaço. A morte passa a ser considerada como o término da vida, o limite, o extremo poder. A desqualificação da morte a transforma no que há de mais secreto da existência, ao mesmo tempo, em que o poder sobre a vida intenta instaurar uma administração calculista da existência. (FOUCAULT, 1988).

Esse controle do corpo pautado no racismo moderno e que influenciou a Educação Física, no final do século XIX e início do XX no Brasil, pode ser visualizado no livro de Costa (1999), quando o autor ressalta que:

[...] as "más inclinações", prevenidas pela inculcação dos bons hábitos, dispensavam o uso de castigos recorrentes e os agentes externos. Seus efeitos eram duradouros, praticamente invisíveis. Implantavam-se gradualmente na "alma dócil", no "corpo tenro e flexível" sem deixar marcas perceptíveis. (COSTA, 1999, p. 175).

O referido autor demonstra que as técnicas de persuasão da moral higiênica eram baseadas em práticas opostas ao que era considerado pelos médicos como vícios e buscavam superar a utilização dos castigos físicos através da domesticação dos gestos. 
O corpo "dócil" é tematizado por Foucault (1999) no livro "Vigiar e Punir", quando o autor fala das transformações dos sistemas punitivos no século XVIII na Europa. Neste caso, a "docilização" dos corpos, enfatizada nas publicações do "Brazil-Medico" analisadas, se refere aos corpos das crianças brasileiras em idade escolar. Uma maneira de conseguir o disciplinamento sem o uso de qualquer outro tipo de castigo, mas sim pela obediência aos preceitos higiênicos.

\section{Notas sobre o processo de sistematização da Educação Física}

No final do século XIX e início do XX, o cenário brasileiro se apresentava repleto de moléstias, sendo a febre amarela, a cólera, a malária, a tuberculose, a peste e as doenças venéreas as mais citadas no "Brazil-Medico". Nessa época havia no Brasil um aumento desordenado da população urbana e não existiam condições de atender a essa demanda. A doença era reconhecida não só por prejudicar o indivíduo e a população, mas também pelo fato de seus contínuos efeitos trazerem malefícios à raça e prejuízo econômico à nação. (A DEMOGRAFIA..., 1887; BARBOSA; VIANNA, 1914; MELLO, 1904; MONCORVO FILHO, 1900).

Nesse contexto, as descobertas científicas eram consideradas importantes para exterminar as grandes epidemias, e os médicos, ao contribuírem com a instrução higiênica dos professores e alunos da escola normal, buscavam disseminar na sociedade os cuidados com a saúde a partir de preceitos científicos modernos.

$\mathrm{O}$ desafio da Higiene moderna, além de suprimir as doenças que eram possíveis e diminuir a mortalidade geral, também era o de difundir para a população as noções indispensáveis aos cuidados com a saúde. Esses cuidados deixaram de ser guiados a partir da relação entre o organismo e o mundo natural e passaram a se basear nos saberes e nas intervenções da Medicina moderna. Com a ambição de se diferenciar das práticas consideradas antigas, a Medicina moderna tinha como prioridade buscar respaldo para se diferenciar dos cuidados com a saúde, fundamentados principalmente na intuição e na magia.

A instauração da positividade da saúde na vida humana surge a partir do final do século XVIII, como ressalta Michel Foucault, ao fazer referência à Medicina europeia que propagava para a sociedade o projeto de alcançar homem saudável ideal. Numa época em que a sociedade considerava a procura pelos prazeres da vida como provocadora de distúrbios na saúde da população e gerava desigualdades sociais, a tarefa do médico tornava-se política. Seu dever era informar, dominar e coagir a população. A vigilância se tornava frequente e 
pulverizada. A consciência médica se generalizava, difundia-se, e cada indivíduo tinha o dever de obter informações sobre os saberes médicos. Para atingir seus objetivos, então, a Medicina moderna não se limitava somente a um conjunto de técnicas da cura e do saber exigidos. Ela abrangia ainda um conhecimento do ser humano saudável, um ser humano modelo, ausente de doença. Com essa postura normativa, não era mais cabível aos médicos unicamente aconselhar sobre a vida em equilíbrio. Esses passam a ter a intenção de regular as relações físicas e morais dos indivíduos e da sociedade. (FOUCAULT, 2001).

Georges Canguilhem (2002), ao se referir à Medicina moderna e discutir a doença na perspectiva da relação entre o normal e o patológico, observa que esta é verificada apenas pela sua variação quantitativa em relação à saúde. A doença é estabelecida a partir de uma identificação localizada em alguma parte do corpo, contribuindo para a ideia de que, se nada for localizado, o ser humano apresenta-se saudável. Esse conceito de saúde, assentado a partir de variações quantitativas, é reforçado pela busca de um tipo idealizado de saúde, pelo que é considerado normal. Todavia, esse normal não é estipulado por variações individuais, mas sim pela relação de uma média estabelecida a partir de mensurações. (CANGUILHEM, 2002).

No cenário epistemológico do final do século XIX e início do XX no Brasil, os médicos-higienistas contribuíram, então, com o embasamento da Educação Física em princípios científicos e com a sua sistematização, com vistas a colaborar com o desenvolvimento das aptidões físicas e intelectuais dos alunos. Era necessário proporcionar o exercício físico de modo racional, separar os alunos que poderiam realizar o curso normal de ginástica daqueles que mereciam cuidados específicos, classificando-os de acordo com suas aptidões físicas. Os alunos doentes eram proibidos de vivenciar os exercícios físicos. A inspeção médica nas escolas tinha como intuito realizar essa seleção. Os alunos matriculados eram submetidos ao exame médico para a confecção da ficha sanitária de cada um. Conforme o Decreto n. 778, de 9 de maio de 1910, referente às instruções para o serviço de inspeção sanitária escolar, encontramos, no Artigo 8, a organização da ficha sanitária. (MONCORVO FILHO, 1911).

$\S 1^{\circ}$ A ficha sanitária será constituida por uma caderneta, na qual serão inscriptos, além do numero de ordem: nome, sexo, filiação, naturalidade, residencia, referencias de vaccinação e revaccinação, medidas anthropometricas e dados resultantes de exame physio-patologico, psychico e outros que possam ser de utilidade.

$\S 2^{\circ}$ A ficha sanitária constituirá o histórico sanitário do alumno e servirá para julgar do desenvolvimento physico do mesmo. 
$1^{\circ}$ Peso, estatura, perímetro toraxico e amplitude respiratória;

$2^{\circ}$ Colorido da pelle e cicratizes cutâneas;

$3^{\circ}$ Hérnias e vícios de conformação;

$4^{\circ}$ Deformação do esqueleto (membros e columna vertebral);

$5^{\circ}$ Conformação do thorax e estado dos respectivos órgãos, com pesquiza dos gânglios peri-bronchicos;

$6^{\circ}$ Estado do orgão da phonação;

$7^{\circ}$ Estado do apparelho digestivo e dos órgãos abdominaes;

$8^{\circ}$ Estado dos órgãos de visão e audição;

$9^{\circ}$ Dados psychicos;

$10^{\circ}$ Observações

Art. $9^{\circ}$ Os dados psychicos obtidos pelo exame servirão para a classificação dos alumnos anormaes.

Paragrapho único. Os alumnos considerados anormaes serão, tanto quanto possível, mantidos em classes especiais, consideradas classes de aperfeiçoamento. (MONCORVO FILHO, 1911, p. 108).

A ficha sanitária pelo que podemos identificar é construída com base nos dados pessoais, ressaltando-se os dados físicos. Além disso, os dados psíquicos serviam para distinguir quem era considerado normal ou anormal. Os indivíduos reconhecidos como anormais eram separados em classes especiais ditas de aperfeiçoamento.

Nota-se que a classificação dos alunos era guiada a partir de uma normalidade ideal, ditada pelos preceitos médicos. No século XIX, a naturalização do termo normal ocorre em diversos espaços sociais, inclusive na reforma hospitalar e na reforma pedagógica. O normal suscita ainda um valor que lhe é atribuído, bem como um antivalor para se opor a este. Como destaca Canguilhem (2002):

[...] a normalização dos meios técnicos da educação, da saúde, do transporte de pessoas e de mercadorias é a expressão de exigências coletivas cujo conjunto define, em determinada sociedade histórica, seu modo de relacionar sua estrutura, ou talvez suas estruturas, com aquilo que ela considera como sendo seu bem particular, mesmo que não haja tomada de consciência por parte dos indivíduos. (CANGUILHEM, 2002, p. 210).

A classificação dos alunos para determinar quem poderia ou não fazer os exercícios físicos, no final do século XIX e início do século XX no Brasil, tinha como parâmetro os procedimentos médicos e contribuiu com esse processo de 
normalização da sociedade. A separação e seleção dos estudantes ocorriam durante as inspeções médicas dos colegiais. Uma inspeção que tinha como objetivo contribuir com a nação, como podemos observar quando Ferreira (1909) diz que:

[...] a inspecção medica dos collegiais... está mesmo no interesse da collectividade, pois tornará mais profícuas as despezas com a instrucção publica e reduzirá, dentro de amplos limites, a deterioração physica, o abastardamento da raça, dando á patria cidadãos instruídos e sadios. (FERREIRA, 1909, p. 376).

Pelo que podemos identificar na citação acima, a inspeção médica dos estudantes tinha como intuito reduzir gastos para o país, reduzindo também a deterioração física.

Nesse cenário pedagógico, a escola tinha como meta corrigir e prevenir imperfeições e o que era considerado como excesso. Desse modo, a Educação contribuía com o controle do espaço e do tempo tendo como parâmetros a ordem, a disciplina e a vigilância, com o intuito de colaborar com a organização pedagógica racional. (ROCHA, 2000).

A Educação Física nesse contexto epistemológico contribuía com a disseminação de uma Educação higienista e higienizadora através do método racional. Esse tipo de Educação perseguia o ideal de reinventar a humanidade sob os auspícios de uma razão alicerçada por ideais iluministas e se propunha a dar origem ao que Gondra (2003) denomina de "Homo hygienicus".

O método racional era preconizado para o programa de Educação higiênica da população. Nesse sentido, uma Educação Física bem orientada tinha como preocupação os aspectos fisiológicos e anatômicos do corpo humano. O método racional deveria proporcionar um exercício adequado para o desenvolvimento harmonioso do organismo, ou seja, uma harmonia que estava relacionada especificamente à simetria dos diferentes grupos musculares. Os músculos do pescoço, dos braços, dos antebraços, do tórax, do dorso, do abdômen, das coxas e das pernas deveriam manter uma disposição bem ordenada entre si e aumentar a resistência.

Percebemos que o método racional colaborava com a instauração do que Soares (1994) denomina de ginástica científica, uma ginástica funcional e fragmentada, que passou a ser inserida como conteúdo de ensino nos ambientes escolares brasileiros no final do século XIX e início do XX.

O exercício físico contribuía com a medicalização da sociedade e com a segregação dos indivíduos de acordo com as diversidades biológicas. A Educação 
Física era considerada instrumento ideal para fabricar indivíduos saudáveis e úteis para o trabalho industrial. Nesse período, defendia-se que o Estado tinha o dever de possibilitar que a escola garantisse a oferta de um programa racional de Educação do corpo para as crianças. (VAGO, 1999a).

Dentre os diversos cenários educativos brasileiros dessa época, o método racional era utilizado com vistas a expor a precisão dos gestos exibidos na execução de exercícios físicos. A exatidão da mobilidade adestrada proposta para o interior da escola poderia contribuir com a construção de gestos capazes de superar o que prevalecia anteriormente, ou seja, a fixidez do corpo.

Da pedagogia imobilista à mobilidade adestrada, a Educação Física contribuiu com a interiorização de cuidados com o corpo em busca de saúde na Educação escolar, chamando a atenção para a vivacidade das crianças. Refutava-se um ensino que dominava os alunos através de estratégias violentas, como a fixidez do corpo, e buscava-se um ensino pela ação, pautado em experimentações, de acordo com a normatização da ideologia de um homem saudável ideal.

O pensamento médico-higienista contribuiu com a construção das bases científicas da Educação Física e com o seu reconhecimento no cenário escolar. A sistematização da Educação Física através do método racional contribuiu com o reconhecimento da existência da cultura física, das expressões do corpo, numa época em que prevalecia um ensino pautado na memorização e na imobilidade.

Essa sistematização da Educação Física era guiada por uma verdadeira anatomia política através da "docilização" dos corpos, se pensarmos como Foucault $(1988,1999)$, pois, ao mesmo tempo em que proporcionava visibilidade aos gestos infantis, visava o controle de suas expressões. Valorizava-se um conhecimento pautado na ordem e na medida, em detrimento da diversidade da cultura. Gestos padronizados tendo como modelo a perfeição das máquinas industriais colaboravam com a Educação e o corpo era tido como instrumento para a aprendizagem.

O ensino se detinha aos aspectos orgânicos do movimento humano, contribuindo com a naturalização das diferenças individuais, culturais e sociais e gerava hierarquias. O método racional utilizado pela Educação Física colaborou com a busca pela perfeição das formas corporais e com a recusa da fealdade. Para Flores (2000), a fealdade referia-se à desarmonia das formas corporais, intensificando a busca pela simetria proposta no ideal apolíneo e tendo como referência o modelo europeu.

No final do século XIX e início do século XX no Brasil, o desejo de branqueamento da raça presente nos ideais da intelectualidade da época contribuiu para a construção de um ideal de beleza pautado nos moldes clássicos da cultura grega, tendo como modelo o povo europeu, considerado como ideal de civilidade. (FLORES, 2000). 
Nesse entendimento de Educação, buscava-se a normalização a partir dos moldes de saneamento e perfeição corporal, sendo sustentada pelo racismo biológico, ou seja, sustentada por práticas que objetivavam controlar a existência, tendo como base a ideologia do ser saudável.

Essa ideologia do homem saudável será potencializada em discursos do século XX e XXI, associando a cultura física aos ditames da cultura de consumo e da indústria do bem-estar. Paralelamente a esse investimento no corpo, cujo estandarte de visibilidade pode ser encontrado no esporte, será viabilizada não só pela Educação Física como componente curricular, mas por vários setores da vida social. Nesse contexto, a Educação do corpo torna-se multirreferencial, sendo necessárias outras investigações sobre o tema no cenário contemporâneo, haja vista que hoje são configurados outros indicadores dessa relação entre corpo, cultura e Educação.

\section{Considerações finais}

Analisar o "Brazil-Medico" configurou-se como um desafio pela evidência de relações entre a Educação escolar e a Educação Física presentes no final do século XIX e início do XX. Este estudo colaborou com reflexões sobre cuidados com a saúde na Educação e apontou elementos sobre a sistematização da Educação Física, tendo como foco o método racional.

Como pudemos observar pelo material analisado, o que prevalecia na Educação escolar das crianças era a imobilidade e a falta de cuidados com o corpo em busca de saúde. O ensino infantil se pautava prioritariamente no método da memorização. Em contrapartida, os médicos, que publicaram no "Brasil-Médico" no período analisado, defendiam um método pautado na ação, na experiência vivida pelas crianças como forma de possibilitar que elas se movimentassem e parassem de decorar palavras. Além disso, esses médicos também defendiam incutir nas crianças regras de higiene e de moral por meio da "docilização" dos corpos.

Com relação aos elementos identificados sobre a sistematização da Educação Física, ressaltamos que num contexto permeado por doenças existia a necessidade dos cuidados com a saúde. Nesse cenário, os médicos-higienistas colaboraram com o embasamento da Educação Física em princípios científicos e com a sua sistematização. Existia a necessidade de proporcionar o exercício físico de modo racional, por meio da separação dos normais e dos anormais, reconhecidos como doentes. A Educação Física era definida pela classificação 
dos alunos para saber quem poderia ou não fazer exercícios físicos. Era pautada no método racional e enfatizava os aspectos fisiológicos e anatômicos do corpo, contribuindo com uma Educação higienista que buscava a simetria dos grupos musculares. A Educação Física nesse contexto buscava a perfeição corporal tendo como padrão o modelo europeu.

Os dados encontrados no periódico "Brazil-Medico" nos oferecem indicadores epistemológicos importantes para compreendermos as bases científicas e pedagógicas da Educação Física no final do século XIX e início do XX. No contexto investigado, a Educação Física contribuiu com a interiorização de cuidados com o corpo em busca de saúde na Educação escolar, trazendo à tona a vivacidade das crianças. A sistematização da Educação Física por meio do método racional contribuiu com o reconhecimento da existência da cultura física, das expressões do corpo, numa época em que prevalecia um ensino pautado na memorização e na imobilidade.

\section{REFERÊNCIAS}

A DEMOGRAFIA entre nós. Brazil-Medico, v. 1, n. 8, p. 57-58, 1887.

AZEVEDO, F. Da educação physica. São Paulo e Rio de Janeiro: Weiszflog Irmãos, 1920.

AZEVEDO, F. Da educação física: o que ela é, o que tem sido, o que deveria ser: São Paulo: Melhoramentos, 1960.

BARBOSA, P.; VIANNA, S. Nosologia e mortalidade da Cidade do Rio de Janeiro. Brazil-Medico, v. 28, n. 11, p. 101-104, 1914.

BARDIN, L. Análise de conteúdo. Lisboa: Edições 70, 1979.

BECKER, J.; PAZTMANN, L.; GROSS, T. Correspondência de Adolpho Lutz: cartas selecionadas. História, Ciências, Saúde - Manguinhos, v. 10, n. 1, p. 313-361, 2003.

CAMBI, F. História da pedagogia. São Paulo: UNESP, 1999.

CANGUILHEM, G. O normal e o patológico. 5. ed. Rio de Janeiro: Forense Universitária, 2002.

CARVALHO, M. M. C. Modernidade pedagógica e modelos de formação docente. São Paulo em Perspectiva, v. 14, n. 1, p. 111-120, 2000.

CLARK, O. Inspecção medica das escolas. Brazil-Medico, v. 30, n. 21, p. 161-163, 1916.

CLARK, O. A organização do serviço de hygiene escolar do Rio. Brazil-Medico, v. 27, n. 15 , p. 201-203, 1923. 
COSTA, J. F. Ordem médica e norma familiar. Rio de Janeiro: Graal, 1999.

ESCOLAS ao ar livre e preventorios. Brazil-Medico, v. 36, n. 2, p. 309, 1922.

FERREIRA, C. A inspecção médica dos collegiais. Brazil-Medico, v. 23, n. 37, p. 375$378,1909$.

FERREIRA, L. O.; MAIO, M. C.; AZEVEDO, N. A. Sociedade de Medicina e Cirurgia do Rio de Janeiro: a gênese de uma rede institucional alternativa. História, Ciências, Saúde-Manguinhos, v. 4, n. 3, p. 475-491, 1998.

FLORES, M. B. R. A política da beleza: nacionalismo, corpo e sexualidade no projeto de padronização brasílica. Diálogos Latinoamericanos, Aarhus, v. 1, n. 1, p. 88-109, 2000.

FONTES, A. Prophylaxia da tuberculose. Brazil-Medico, v. 35, n. 2, p. 98-103, 1921.

FOUCAULT, M. História da sexualidade 1: a vontade de saber. Rio de Janeiro: Graal, 1988.

FOUCAULT, M. Vigiar e punir. 21. ed. Petrópolis, RJ: Vozes, 1999.

FOUCAULT, M. O nascimento da clínica. 5. ed. Rio de Janeiro: Forense Universitária, 2001.

GÓIS JUNIOR, E.; LOVISOLO, H. R. A educação física e concepções higienistas sobre raça: uma reinterpretação histórica da educação física brasileira dos anos de 1930. Revista Portuguesa de Ciências do Desporto, v. 5, n. 3, p. 322-328, 2005.

GONDRA, J. G. A sementeira do porvir: higiene e infância no século XIX. Educação e Pesquisa, v. 26, n. 1, p. 99-117, 2000.

GONDRA, J. G. Homo hygienicus: educação, higiene e a reinvenção do homem. Cadernos Cedes, v. 23, n. 59, p. 25-38, 2003.

HYGIENE da infância. Brazil-Medico, v. 17, n. 14, p. 137, 1903.

MELLO, A. Vaccinação obrigatória. Brazil-Medico, v. 18, n. 32, p. 323-324, 1904.

MONCORVO FILHO, A. Subsidio ao estudo da mortalidade infantil no Rio de Janeiro. Brazil-Medico, v. 14, n. 35, p. 307-309, 1900.

MONCORVO FILHO, A. Notas para um guia de hygiene escolar. Brazil-Medico, v. 25, n. 4, p. 33-36, 1911.

PIÇARRA, L. O ensino da hygiene na escola primaria. Brazil-Medico, v. 22, n. 33, p. 326-328, 1908.

ROCHA, H. H. P. Prescrevendo regras de bem viver: cultura escolar e racionalidade científica. Cadernos Cedes, v. 20, n. 52, p. 1-19, 2000.

SÁ, C. O ensino da hygiene nas escolas primarias. Brazil-Medico, v. 36, n. 27, p. 21-26, 1922. 
SCHWARCZ, L. M. O espetáculo das raças: cientistas, instituições e questão racial no Brasil. São Paulo: Companhia das Letras, 1993.

SOARES, C. L. Educação física: raízes européias e Brasil. São Paulo: Autores Associados, 1994.

VAGO, T. M. Cultura escolar, cultivo de corpos: educação physica e gymnastica como práticas constitutivas dos corpos de crianças no ensino público primário de Belo Horizonte (1906-1920). Tese (Doutorado) - Programa de Pós-Graduação em Educação, Universidade de São Paulo, São Paulo, 1999a.

VAGO, T. M. Início e fim do século XX: maneiras de fazer educação física na escola. Caderno Cedes, v. 19, n. 48, p. 30-51, 1999 b.

Texto recebido em 24 de março de 2015. Texto aprovado em 18 de junho de 2015. 
